says Ziauddin Sardar, a UK-based writer on the cultures of Islam and science. "But it cannot provide the atmosphere of criticism and openness that scientific research needs to flourish."

"The university sounds wonderful on paper, but I'm sceptical it will bear fruit," adds Nader Fergany, director of the Almishkat Centre for Research in Giza, Egypt. "Saudi Arabia has produced expensive white-elephant universities before." The King Abdulaziz City for Science and Technology, for instance, established in 1977, has not had any significant international impact. And Fergany doubts that the regime can deliver on its promise of autonomy. A first test, he says, will be whether a non-Saudi is allowed to be founding president.

Fergany, who was lead author of the landmark series of Arab Human Development Reports published by the United Nations Development Programme between 2002 and 2005 , also doubts that the university represents a move towards greater freedom. "I would be less pessimistic if the kingdom had an overall atmosphere of opening up and reform," he says. "But the restrictions of the regime are so pervasive that an isolated campus on the Red Sea is not going to make an impact on the country."

Another sticking point is relations with Israel, a research powerhouse in the region that shares many interests, such as water, with KAUST. Mulla says that Saudi Arabia cannot cooperate "at the present time" with countries with which it does not have diplomatic relations - which would mean no formal collaboration between KAUST and Israeli institutions.

"It's a delicate issue," says Mulla, and it is being left to the side for the moment. The board has agreed to accept this situation, after receiving assurances that KAUST will be free to recruit Israeli faculty and students.

Declan Butler

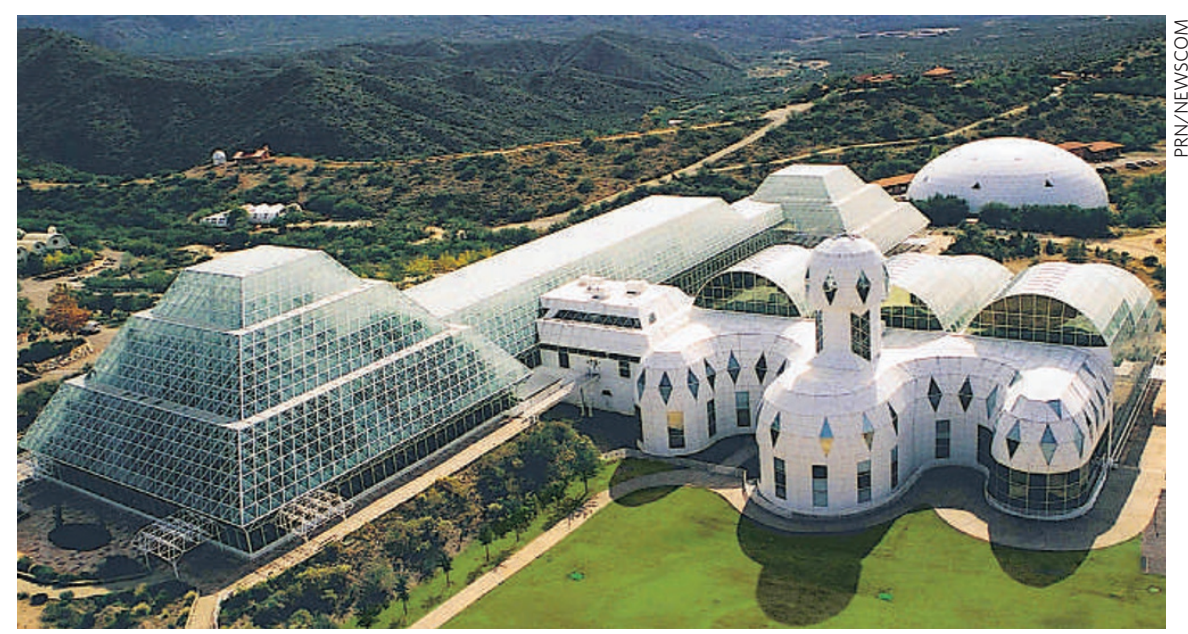

Tourists still flock to the desert complex that once housed an experiment in self-sustainability.

\title{
Biosphere 2 finds a buyer
}

The terrarium Biosphere 2 is to become a research conversation piece for a new housing development in Arizona.

Last week, the 1.4-hectare glass enclosure and about 700 hectares of land around it in the desert foothills outside Tucson were sold for US\$50 million. Its new owner, CDO Ranching \& Development, is securing permits to build 1,500 houses around the edifice.

The University of Arizona in Tucson is negotiating with the new owners to lease the facility for climate experiments.

Texas oil billionaire Ed Bass spent about $\$ 200$ million on the project. In 1991, the glass bubble became the centre of worldwide attention when eight people were sealed inside for a two-year 'experiment' in self-sustainability. But the project failed - oxygen had to be pumped in from outside, and the experiment ended early amid much squabbling both inside and outside the bubble.

By 1996, Columbia University in New York City had taken over managing the facility. It planned extensive research projects on climate, soil and plant dynamics. But Columbia withdrew from the arrangement at the end of 2003 as part of a litigation settlement with the facility's corporate owner, Decisions Investments.

The University of Arizona had been negotiating for several years to attempt to buy the Biosphere 2 complex, now largely used for tours by the curious. Local politicians also want it preserved as it as a landmark that attracts tourists. Rex Dalton
The proposed Advanced Technology Solar Telescope (ATST) would tower above a cluster of smaller facilities already in use a few hundred metres from the Haleakala summit, traditionally revered by Hawaiians as the home of the mist goddess Lilinoe.

With its four-metre aperture, ATST would be the largest solar telescope ever built, and it is intended to allow solar physicists to better understand the dynamics of the Sun's magnetic field. The project is spearheaded by the National Solar Observatory, and collaborators include the University of Hawaii's Institute for Astronomy and the US Air Force Research Laboratory. If the \$230-million project wins approval, construction may begin as early as 2009 .

Installing the ATST high up, where there is less air turbulence, and in Maui's relatively dust-free, stable atmosphere, would give physicists the best chance of resolving magnetic features on the Sun's surface spanning some 30 kilometres across, explains Craig Foltz, programme manager at the US National Science Foundation. "Believe me, if we could build it smaller and lower, we would," he adds.

But in a letter last month to the
National Science Board, which will need to approve the project, the National Park Service's regional director Jonathan Jarvis argued that replacing Haleakala's summit with a man-made structure as the tallest feature on Maui would completely alter the visitor experience. And with the only access to the observatory site being through the national park, he is worried that construction vehicles will damage the narrow 1930 s road and harm endangered nene and 'ua'u bird populations.

Because the Haleakala summit carries cultural and spiritual significance for Hawaiian people, an added concern is that further development will erode the spiritual value of the mountain top for native Hawaiians.

“We're not against science and the acquisition of knowledge, but science has ethics," says Ed Lindsey, a native Hawaiian and president of Maui Cultural Lands, a Maui-based organization set up to protect and restore Hawaiian cultural resources. "If you destroy things that have meaning to native people, you ultimately destroy the people." Lindsey says Maui Cultural Lands is prepared to file a lawsuit if all else fails.

Lucy Odling-Smee 